\title{
Is Trauma a Social Phenomenon That Leads to Gang Involvement?
}

\author{
Morgan Leksen \\ Department of Sociology, MacEwan University
}

\begin{abstract}
This paper examines the effects of trauma on youth gang involvement. It focuses on the repercussions that trauma can have on youth, which may result in them looking for like-minded adolescents who are in gangs. The need for support can stem from the reoccurring trauma that the individuals face at an early age and the gang can appear as a safe haven from their lives. This paper argues that the experiences of direct and indirect trauma can put these adolescents on a different life path compared to their peers. Youth need to be actively supported in their families and in the education system in order to succeed. The way society reacts and responds to adolescents who are experiencing trauma will set the tone on how they develop in the future. These youth should be seen as a societal responsibility, and when they are left behind or fall through the cracks of certain social institutions, it should be seen as a failure by the social system and not the individual being seen as a failure. Because of these failures, trauma is a social phenomenon that can lead to youth gang involvement.
\end{abstract}

\section{Introduction}

Why do youth join gangs? Although there are many factors that play a role, this paper discusses the effects of trauma on youth gang involvement. The repercussions of experiencing trauma as young children can push them into a search for like-minded adolescents who are involved in the gang lifestyle. These youth should be defined as being at-risk before they have entered into gang involvement because the majority of them have experienced trauma in a variety of areas. These experiences can include exposure to violence, loss of their home, loss of a parent, and substance abuse in the home. The recurring trauma faced at an early age can lead to the decision to join a gang to fill the void that the youth has been experiencing in their life. Once the adolescent has joined a gang, they may experience additional trauma that further classifies them as being at-risk. The externallycaused childhood trauma is then compounded by personal substance abuse, mental health deterioration, and suicide attempts (Petering, 2016, p. 1). However, the issue is that society views this trauma as an individual issue, when it needs to be acknowledged as a social issue and these youth seen as a societal responsibility. This outlook on at-risk youth switches the focus from the individual and is able to shed light on trauma being a social phenomenon that can lead to gang involvement.

Gang involvement as a result of trauma needs to be seen as a social issue because the adolescents that are getting involved in gang activity are individuals that have fallen through the cracks of different social institutions, including the education system and the family. Craig, Vitaro, Gagnon and Tremblay (2002) note that "alienation from parents [is] the initial cause of adolescents turning toward delinquent and gang activity" and this lack of family support can lead to youth being more open to alternative supports that being in a gang can provide (p. 54). The trauma of being alienated from their family is a leading factor in gang involvement; yet, society reacts to the youth being deviant and involved in a gang, rather than focusing on gang involvement being the result of that trauma. The education system is also directly involved in the youth's lives, but adolescent gang members are "more likely to have been suspended from school..." and also feel that the gang gives them "social supports that are unavailable from other sources such as family, school, and non-delinquent peers" (Petering, 2016, pp. 3-4). Developing a social analysis of the impact of trauma on youth gang involvement requires a complex discussion. There is also a need to critically assess the factors that are addressed, in order to properly detail why trauma affecting youth should be considered a social phenomenon rather than solely an individual concern. The phrase social phenomenon can be used to describe how society's negative responses to trauma and the failures of the social institutions can have a huge effect on the lives of the youth and that it must be recognized as the core problem. This paper provides some background information, including defining trauma, the failures of the social institutions such as 
family and the education system, and how this can ultimately result in gang involvement.

\section{The Effects of Trauma}

Arnold and Fisch (2011) define trauma as "a medical term used to denote serious injury to the human body," but that refers to physical trauma and not psychological trauma, which can create lasting effects long after childhood (p. 10). Psychological trauma is separate from physical trauma and can be seen as a response to an event. The traumatic event can create "psychological trauma when it overwhelms the individual's ability to cope...[and] the individual may feel emotionally, cognitively, and physically overwhelmed" (Giller, 1999, p. 1). The traumatic event that an individual is faced with does not have to be of physical nature and the conditions experienced often include "abuse of power, betrayal of trust, entrapment, helplessness, pain, confusion, and/or loss" (Giller, 1999, p.1). It is easy to understand how physical and psychological trauma can affect an individual, however, what is not regularly discussed is the effects of social trauma. Social trauma can describe how an individual's family, educational experiences, and other community experiences can contribute to and/or influence how an individual is impacted by trauma. For example, if a youth is treated well within social institutions and those institutions respond to trauma appropriately, that youth has a better chance of feeling supported. On the other hand, if the social institutions respond negatively to youth that have experienced trauma, it has the ability to worsen the traumatic experience for those individuals.

Youth development and their experiences are related to posttraumatic stress disorder because guardians/parents are supposed to provide comfort and security, but when there is no feeling of safety, youth may have an "experience of shattering inside", which leads to the youth feeling misunderstood and losing the sense of identity (Arnold \& Fisch, 2011, p. 12). The youth's ability to develop and succeed in society is largely affected when they are dealing with symptoms of post-traumatic stress disorder, because it hinders their ability to function in social and educational settings. In circumstances where a youth is repeatedly exposed to traumatic events and lacks that safe person, their development is subsequently impacted, which is detrimental in long-term approaches on developing relationships (Arnold \& Fisch, 2011).

Trauma may be direct or indirect; however, the outcomes that result from both of these are very similar. When an individual has experienced direct trauma, they "have either experienced the event firsthand or been a witness to the event as it occurred to others" (May \& Wisco, 2015, p.1). Indirect trauma is described as "being confronted with a trauma" and includes "learning about unexpected or violent death, serious harm, or threat of death or injury experienced by a family member or close associate" (May \& Wisco, 2015, pp.1-2). Indirect trauma can explain how youth do not need to be physically harmed in order to be traumatized and have their lives effected by an experience in their home. This type of trauma can easily go unnoticed and that can lead to the youth feeling misunderstood and seeking attachment through other outlets.

General strain theory proposes that three types of experiences can lead to delinquency: "(1) strain as the actual or anticipated failure to achieve positively valued goals, (2) strain as the actual or anticipated removal of positively valued stimuli, and (3) strain as the actual or anticipated presentation of negatively valued stimuli" (Agnew, 1999, p. 47). All three of these strains can contribute to youth delinquency; however, this paper will focus on the idea that strain occurs when youth experience a loss in their social institutions, which can lead to them presenting with negative behaviours. Agnew argues that "strains or stressors increase the likelihood of negative emotions like anger and frustration" (Agnew, 2001, p. 319), which can account for the actions that a youth may be expressing due to the trauma that they are experiencing in their home life. The youth can be experiencing what Agnew (2001) describes as "the loss of positive stimuli" which can ignite "the presentation of negative stimuli” (p. 319). The role of family, peers, and teachers can be seen as positive stimuli in an adolescent's life, therefore if they were to lose that support whether it was through death, "the withdrawal of parental love", or through other types of losses it can be detrimental in their future (Brezina, 2017, p. 4). When a youth experiences the loss of the positive stimuli, they can react with negative behaviours, which can present in a variety of ways. For example, the youth can begin to have physical altercations or demonstrate verbal outbursts (Agnew, 2001, p. 319). When this is put into perspective it shows the importance of social institutions and the ability to notice when an adolescent's negative reaction is brought on by a loss of positive stimuli. It is possible that the loss of positive stimuli could be the result of a traumatic event that occurred in the social institution such as the youth experiencing parental neglect. When this type of traumatic event occurs, it would then fall on the teachers and the workers in the educational system to notice the signs of trauma. This further supports the idea of trauma being a social phenomenon because it shows that it takes more than the sole individual to deal with trauma and the effects it can have on the youth. Trauma that a youth experiences can have negative effects on their wellbeing and their sense of identity, however the support from the social institutions of family and education can determine the fate of that youth. 


\section{The Roles of Social Institutions}

Parents struggle to provide the comfort and security their children need when there is a history of intergenerational trauma in the family. When a parent has experienced their own trauma it "may interfere with parenting capacities in ways that adversely affect child development, such as decreasing parents' emotional availability and responsivity to children's needs" (Kerig \& Alexander, 2012, p. 206).

Trauma has the ability to become layered for individuals that have not had the resources to overcome its effects, therefore when a parent has not dealt with their own trauma, they resort to maladaptive defensive processes when dealing with their children's trauma (Silverman \& Lieberman, 1999). The method of avoidance has the potential to further traumatize the youth and leads the parents to "respond in ways that are nonempathic and invalidating" (Kerig \& Alexander, 2012, p. 207). These findings are relevant because they provide evidence showcasing how early experiences can shape the outlook of a youth's future. It also shows how experiences of trauma can lead to a lack of trust in systems and people, creating the previously mentioned void that can result in a search for belonging, which may be provided by a gang. The failures in the family system can stem from a variety of different sources that can include intergenerational trauma, as well as parents failing to notice the signs of trauma and how to support the youth. However, intergenerational trauma is more widely known in the context of the experiences of Indigenous children in residential schools and how that can affect generations to come, and not solely the individual directly exposed to that traumatic experience. The parents are often not aware that they are transferring the effects of their own trauma onto their children, and they sometimes do not realize that their behaviour is a result of the trauma that they experienced in the residential schools (O'Neill, Fraser, Kitchenham and McDonald, 2016, p.1). The trauma that was felt by a youth's grandparents can have effects on their parenting skills with their children, and that experience can translate into how the parents of current youth will treat them. O'Neill and colleagues (2016) explain that when youth are in a family structure where the parent/guardian "is the source of fear or is reacting out of fear..." it leaves the children feeling stuck in a situation that has the ability to be traumatic (p. 176). When youth have been brought up in homes where they cannot express their feelings, it can cause them to feel lost and they do not know how to regulate their own emotions because they were not taught healthy coping mechanisms. The adolescents have no choice but to enter the education system with their unresolved trauma and that has the ability to exacerbate the situation.

The development of relationship-building skills is greatly affected by the early trauma experiences of youth, therefore creating difficulties in connecting in a healthy manner with others, such as teachers and peers (Arnold \& Fisch, 2011). These youth "repeat the same patterns of behaviour with their teachers that they have experienced at home", resulting in a similar level of distrust of those in authority if their emotional and physical needs are not being met at home (Arnold \& Fisch, 2011, p. 161). The education system is based on individual successes and failures. It involves the individual being able to self-monitor their behaviour and regulate their emotions. The education system expects certain grades of the individuals in their care, and it will punish those that do not achieve them. This makes it easy to continue the trauma cycle, because the education system is not set up to prioritize trauma or the situations that could be happening in the youth's home life. In order for youth to be successful, they need to be able to form a strong bond with those in the educational structure, and it will require the institutions to develop safety nets for these students, so that these effects do not determine the course of their entire lives. The educational system is one of many societal institutions that can directly impact the feeling of lacking belonging for the youth which can result in unsafe actions as youth.

Arnold and Fisch's (2011) research on trauma and youth development can also be used in conjunction with Cooley's theory of the looking glass self to dissect the development of identity based on youths' experiences and how they see themselves in a society (Siljanovska \& Stojcevska, 2018). As stated above, the educational system can contribute to this image and may be able to change the youth's definition of themselves. As Cooley (1902) states, "we develop our own self through the condemnation of others"; as such, there is great value in the treatment of youth in schools because of how they may compare themselves to those who are shunned in society (as cited in Siljanovska \& Stojcevska, 2018, p. 64). The adults that are placed in the educational system to teach and take care of the youth can have a tremendous effect on their upbringing. When youth are not treated well in school by the people put in place to protect them it can damage their sense of self. The way youth see themselves can be greatly influenced by people in educational institutions, and this effects how an individual compares themselves to others. If a youth is condemned within a school setting while also experiencing a lack of security at home, they may change their "true self according to other's criteria to become a new person who behaves differently" (Siljanovska \& Stojcevska, 2018 , p. 66). The early experiences of trauma and acceptance or rejection within the educational system, combined with the development of self-identity, leads to the discussion of gang involvement and how these youth find it to be an acceptable choice. 


\section{Gang Involvement}

Descormiers and Corrado (2016) discuss initiation into gangs and reasons for youth to be interested in joining gangs. Their mixed-methods approach to analyzing data on initiation tactics, level of violence required, and subsequent violent actions by newly appointed members of a gang provide background information on how youth can see gangs as an ideal environment for belonging. One striking example within this article was regarding a female youth who was "blessed-in" due to her previous behaviour that was known to the gang. This behaviour deemed her to be an acceptable member, due to her family history of gang involvement and her reputation as someone who would fit in. The idea of being asked to join a gang because of one's history through their parents and other family members adds to the discussion of how that trauma affects the acceptability of gang involvement. Trauma becomes involved in this process because if a youth is from a gang involved family, they have already witnessed the brutality of gangs throughout their lives. The trauma could be direct or indirect and both could determine their choices to join the gang. The youth that have witnessed their own families being involved in gangs and the repercussions of those life choices can be traumatizing for youth. The gang lifestyle and the violence that comes with it cannot go unseen by the youth and that can have lasting effects of trauma.

Other findings that are important to consider are the motivating factors for joining the gang, especially for those who were required to undergo the violent initiations. For those who were "blessed-in", the reasons for joining, such as "respect" and "protection" were lower than those who were required to prove themselves through the initiation process (Descormiers \& Corrado, 2016, p. 1353). The one major similarity between all youth members was regarding how these youth were introduced to the gang lifestyle, mainly through family members and associates, which can continue to perpetuate the idea that unsafe parenting/family can lead to further detrimental issues throughout life (Descormiers \& Corrado, 2016). When there is a systematic breakdown of the parental and educational institutions, it opens the youth up to negative influences and could lead to gang involvement. When parents do not know how to support their children through trauma, or they live a life that is unsafe for their children, it leads to multiple failures in the system. These failures spill over into the educational system and if unfair treatment continues in that social institution then it can lead to that child searching for like-minded individuals in society.

Descormiers \& Corrado (2016) reveal the most important reason for this research, stating "if individual motivations were understood before youth joined gangs, then those motivations could serve as a basis for designing interventions for those so-called high-risk youth" (p. 1357). There is a great need to understand the motivations of these youth and listen to their experiences prior to their incarcerations, injuries and/or deaths, as they are not only individuals but also members of a larger society. Motivations for joining a gang can be seen as an individual's choice and societal situations are not accounted for in the discussion. As discussed, mistreatment in the social institutions of family and education can lead to trauma in a child's life. If that trauma is not dealt with appropriately by individuals in the social institutions the child is left feeling lost in society and does not know where they can turn to next. Understanding how trauma can become a motivation for gang involvement is crucial to being able to stop the cycle. Identifying motivations can be completed through understanding characteristics of youth gang members, in order to assess early signs of high-risk behaviour.

\section{Craig, Vitaro, Gagnon and Tremblay (2002) provide an} analysis of characteristics that are highly likely to be seen in youth gang members, information about the mindset of youth prior to their gang involvement, and how their outlooks contribute to their recruitment by gangs. Craig and colleagues (2002) included 142 boys, aged 11-14, in their study to assess their backgrounds, characteristics and family history (p. 53). Their research also included input from parents and teachers, describing signs of delinquent behaviour prior to gang involvement; this included the presence of aggression and/or fighting with peers. This shows that the upbringing and the family history of these youth can have an effect on the youth, and it can contribute to the youth being recruited by the gang. The parents and teachers had also noticed that the youth had been spending time with other delinquent youth, which can cause them to place labels on other delinquent youth. If parents and teachers were more prepared for dealing with signs of trauma and saw the child as their responsibility, then there may be a chance of stopping gang involvement before it happens.

Craig and colleagues (2002) state that "belonging to a gang would not impact significantly on delinquent activities since the propensity for that behaviour would already exist before belonging to a gang" (p. 54). This means that youth who have experienced trauma and are not fully supported in their social institutions have a greater likelihood of behavioural problems that make it easier to transition into the gang lifestyle. The loss of identity and lack of trust are only two examples of what can impact youth to engage in delinquent activities prior to gang involvement. It is the idea that youths' experiences within the failures of social institutions start way before they connect with gangs. The notion that this behaviour and expression of delinquency already exists can be used to further analyze how an individual's history and experiences can influence their decisions to join a gang. 
In comparison to Descormiers \& Corrado's (2002) findings, there are many similarities regarding the importance of a young person's history and rejection from prosocial peers/society and their future involvement in gangs.

However, Craig and colleagues (2002) go into further detail about the impact of drug and alcohol use on the longevity of a youth's gang involvement. Trauma can contribute to the longevity of the youth's gang involvement because if the youth was not taught healthy coping mechanisms, "inner-city youth often encounter numerous opportunities for criminal coping, such as gang membership and drug selling" (Brezina, 2017 , p. 9). The gang involvement is there to fill a void that the youth has been missing; however, it comes with negative coping mechanisms such as crime and substance use. The comparison between long-term gang involvement and youth who were not involved in gangs at all provides some insight into how society can influence a youth's behaviour and ability to stay away from gang involvement (Craig et al., 2002). The most relevant finding within this article is that "the problem behaviours associated with becoming gang members emerge before age 10" (Craig et al., 2002, p. 67).

Since there seems to be enough evidence to suggest this age, there needs to be more research on how to spot the signs early enough for interventions in schools and other institutions that can create a significant impact.

Although these articles provide insight on the type of youth that belong to gangs and how their past behaviours may dictate their future membership in gangs, there appears to not be enough data regarding membership and history of trauma. Petering (2016) provides information on childhood trauma, such as sexual abuse, physical intimate partner and/or interpersonal violence and homelessness, and its influences on gang involvement. Using self-reporting methods for homeless youth, Petering (2016) gathered information on whether a youth identified as either a gang member, affiliate or non-involved (p. 74). Throughout this article, there is significant information that continues to verify the need for societal intervention rather than individual interventions for youth gang involvement. Many of the youth describe their experiences of abuse and lack of safety, which further puts them in high-risk situations such as homelessness, violence within a gang and/or mental health illnesses (Petering, 2016). The findings from this study indicate that there is higher percentage of drug use among gang-involved youth, which can also have an impact on the overall society and its institutions (Petering, 2016, p. 77-78). Petering (2016) shares valuable data that links gang involvement to a number of issues that we face in society, and again, these issues can only be resolved with institutional levels of intervention.

\section{Discussion and Conclusion}

The research that was analyzed provides the groundwork for possible solutions that can be proposed to fight youth gang involvement, but only if it becomes a societal issue. In order to address trauma as a social phenomenon, society would need to stop blaming individual youth for consequences that are brought on by these social institutions, and instead focus on how to build up that young person in order for them to have more positive experiences in society. The studies on gang-involved youth were developed mainly within institutions, such as jail or health organizations, which showcases the necessity to utilize other institutional systems to intercept the youth before there is more damage caused to their self-image and feelings of belonging.

The institution of the family is expected to be there to support youth and be a place of safety. It can be easy to miss the signs of trauma and it takes work for parents to become fully aware of when their children are experiencing trauma outside of the home. Nonetheless, it is their responsibility to be able to respond appropriately to the trauma once it has come to light. If the parent cannot help their child because they have not had the chance to cope with their own trauma, they need to be willing to reach out for help. The parents have to be able to reach out to other institutional structures available to them, such as the education system. The youth are a societal responsibility and that means that everyone has to work together in order to support the individual. The family would need to stop placing blame on their children for behaviours that they cannot control and take the time to realize that the solutions cannot be found within the youth, but within their social institutions.

The implication surrounding the educational system is that trauma cannot be ignored and must be dealt with appropriately in this institution. Teachers cannot be absolved of responsibility in rebuilding the level of trust that these youth have in society, and although rebuilding this sense of safety can be a great burden, it is necessary. Teachers can accomplish this by recognizing that there may be a traumatic history that comes with a particular young person and trying to understand that there are underlying issues behind the behaviour of the child in the classroom (Arnold \& Fisch, 2011). When a youth is missing school or has multiple outbursts in the education system, the blame is placed on that youth and they are treated as though it is a singular problem. The teachers have to take responsibility for the youth while they are in their care because they are not solely there to educate youth, but also there to protect and nurture them for up to twelve years of their lives.

At-risk youth that have dealt with trauma should feel supported in these social institutions because they are supposed to be places of safety, however they are also spaces 
that can cause more trauma. The outlook that society currently has is to react to youth outbursts at home or school as individual problems. The necessary shift to acknowledging that youth are a societal responsibility needs to be the first step in order to make real change. This needs to be done before a youth feels that they need to search elsewhere for support. Gang involvement may seem like an ideal solution to youth who are accustomed to violence and/or being thought of as deviant, but it can negatively impact youth in a manner that may be irreversible.

\section{References}

Agnew, R. (2001). Building on the foundation of general strain theory: Specifying the types of strain most likely to lead to crime and delinquency. Journal of Research in Crime andDelinquency, 38(4), 319-463. DOI: 10.1177/0022427801038004001

Agnew, R. (1999). Foundation for general strain theory of crime and delinquency. Criminology,30(1),47-87. DOI: 10.1111/j.17459125.1992.tb01093.x

Arnold, C. \& Fisch, R. (2011). The impact of complex trauma on development. Lanham, MD: The Rowman \& Littlefield Publishing Group, Inc.

Brezina, T. (2017). General strain theory. Oxford Research Encyclopedia of Criminology, 1-24. Retrieved from https://oxfordre.com/criminology/view/10.1093/acrefore/97801902 64079.001.0001/acrefore-9780190264079-e-249?print=pdf

Craig, W.M., Vitaro, F., Gagnon, C. \& Tremblay, R.E. (2002). The road to gang membership: Characteristics of male gang and nongang members from ages 10-14. Social Development, 11(1), 53 68. DOI: $10.1111 / 1467-9507.00186$

Descormiers, K. \& Corrado, R. (2016). The right to belong: Individual motives and youth gang initiation rites. Deviant Behaviour, 37(11), 1341-1359. DOI: $10.1080 / 01639625.2016 .1177390$

Giller, E. (1999). What is psychological trauma? Retrieved from http://www.theannainstitute.org/What\%20Is\%20Psychological\%20 Trauma.pdf

Kerig, P.K., \& Alexander, J.F. (2012). Family matters: Integrating trauma treatment into functional family therapy for traumatized delinquent youth. Journal of Child \&Adolescent Trauma, 5(3), $205-$ 223. DOI: $10.1080 / 19361521.2012 .697103$

O’Neill, L., Fraser, T., Kitchenham, A. \& Mcdonald, V. (2016). Hidden burdens: A review of intergenerational, historical and complex trauma, implications for indigenous families. American Psychological Association, 74(1), 173-186. DOI: 10.1007/s40653016-0117-9

May, C.L. \& Wisco, B.E. (2015). Defining trauma: How level of exposure and proximity affect risk for posttraumatic stress disorder. Psychological Trauma: Theory, Research, Practice, and Policy, 18. DOI: http://dx.doi.org/10.1037/tra0000077

Petering, R. (2016). Sexual risk, substance use, mental health, and trauma experiences of gang-involved homeless youth. Journal of Adolescence, 48, 73-81. DOI: 10.1016/j.adolescence.2016.01.009

Siljanovska, L. \& Stojcevska, S. (2018). A critical analysis of interpersonal communication in modern times of concept "looking glass self (1902)" by Charles Horton Cooley. SEEU Review, 13(1), 62-74. DOI: 10.2478/seeur-2018-0007

Silverman, R. C. \& Lieberman, A. F. (1999). Negative maternal attributions, projective identification, and the intergenerational transmission of violent relational patterns. Psychoanalytic Dialogues, 9(2), 161-186. DOI: 10.1080/10481889909539312

Statistics Canada. (2019). A portrait of Canadian youth. Retrieved from https://www150.statcan.gc.ca/n1/en/pub/11-631-x/11-631x2018001-eng.pdf?st=G13Rby_j 